Supplement of SOIL, 7, 83-94, 2021

https://doi.org/10.5194/soil-7-83-2021-supplement

(c) Author(s) 2021. CC BY 4.0 License.

(c) (i)

Supplement of

\title{
Stable isotope signatures of soil nitrogen on an environmental-geomorphic gradient within the Congo Basin
}

Simon Baumgartner et al.

Correspondence to: Simon Baumgartner (simon.baumgartner@uclouvain.be)

The copyright of individual parts of the supplement might differ from the article licence. 


\section{Supplement - Methods}

\section{Methods for aquatic TDN and DON export}

At each forest site, water samples have been taken from a nearby stream with a 2L HDPE bottle. Samples were taken fortnightly $(\mathrm{N}=22$ for lowland forest, $\mathrm{N}=19$ for montane forest and $\mathrm{N}=5$ for Miombo woodland) and discharge was measured at concrete flumes with a fixed width, by measuring water level and discharge with a mechanical flowmeter (General Oceanics Inc, Miami, US). Water samples got filtered through a $0.7 \mu \mathrm{m}$ glass microfibre filter (Whatman, UK). The filtrated samples were immediately stored in a freezer and transported to Belgium for chemical analysis. $\mathrm{NH}_{4}{ }^{+}$was determined colorimetrically by the salycialte-nitropusside method (Mulvaney 1996) on an autoanalyzer (AA3; Bran and Luebbe, Norderstedt, Germany). $\mathrm{NO}_{3}{ }^{-}$was also determined colometrically with the same autoanalyzer in form of $\mathrm{NO}_{2}^{-}$after reduction of $\mathrm{NO}_{3}{ }^{-}$in a $\mathrm{Cd}-\mathrm{Cu}$ column followed by the reaction of the $\mathrm{NO}_{2}^{-}$with $\mathrm{N}-1$-napthylethylenediamine to produce a chomophore. Total dissolved nitrogen (TDN) was measured by adding $1: 1$ oxidizing solution of $\mathrm{NaOH}, \mathrm{H}_{3} \mathrm{BO}_{3}$, and $\mathrm{K}_{2} \mathrm{~S}_{2} \mathrm{O}_{8}$ to the sample and autoclave it for $1 \mathrm{~h}$ at $121^{\circ} \mathrm{C}$. This process converted $\mathrm{NH}_{4}{ }^{+}$and the dissolved organic $\mathrm{N}(\mathrm{DON})$ into $\mathrm{NO}_{3}{ }^{+}$(Lachouani et al. 2010). Yields were calculated by dividing the annual exports by the catchment area. The catchment area was determined using the GPS positions of the flumes and calculating upstream area in a 30-m SRTM derived digital elevation model (DEM) (NASA JPL).

\section{Supplement - Results}
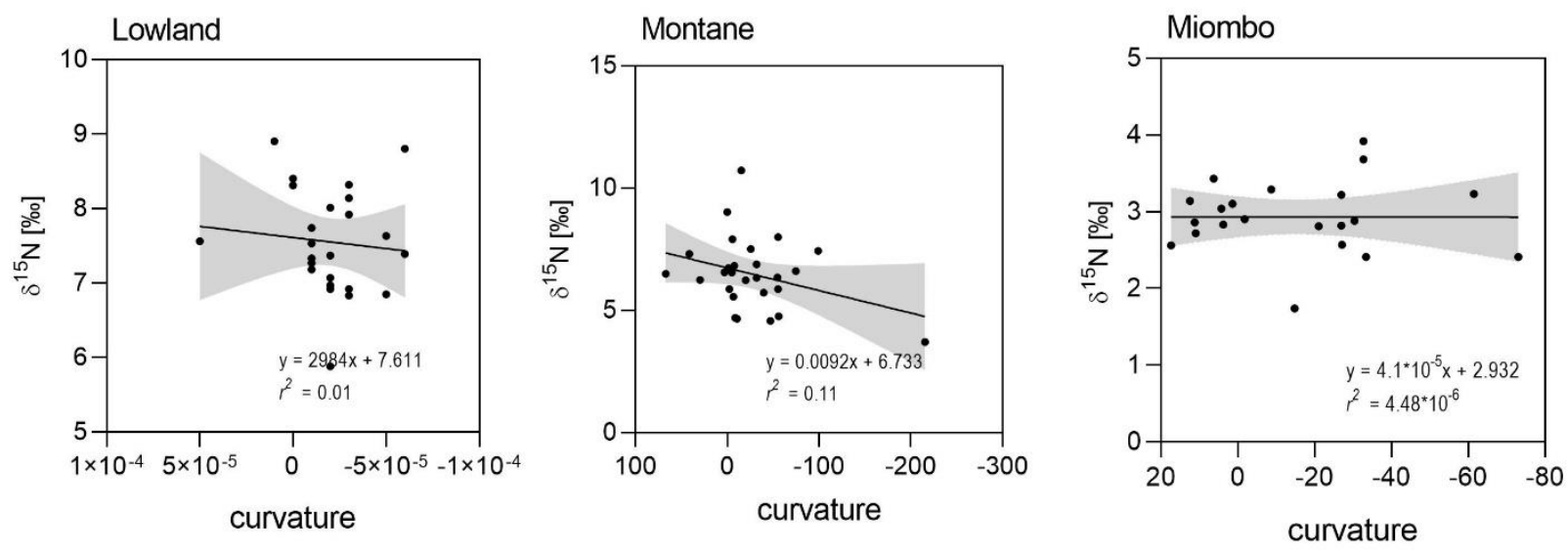

Figure $\mathrm{S} 1: \delta^{15} \mathrm{~N}$ in topsoil $(0-20 \mathrm{~cm})$ plotted against the curvature of the sampling spot. Positive curvature values represent concave landforms, while negative values represent convex landforms. 
a)

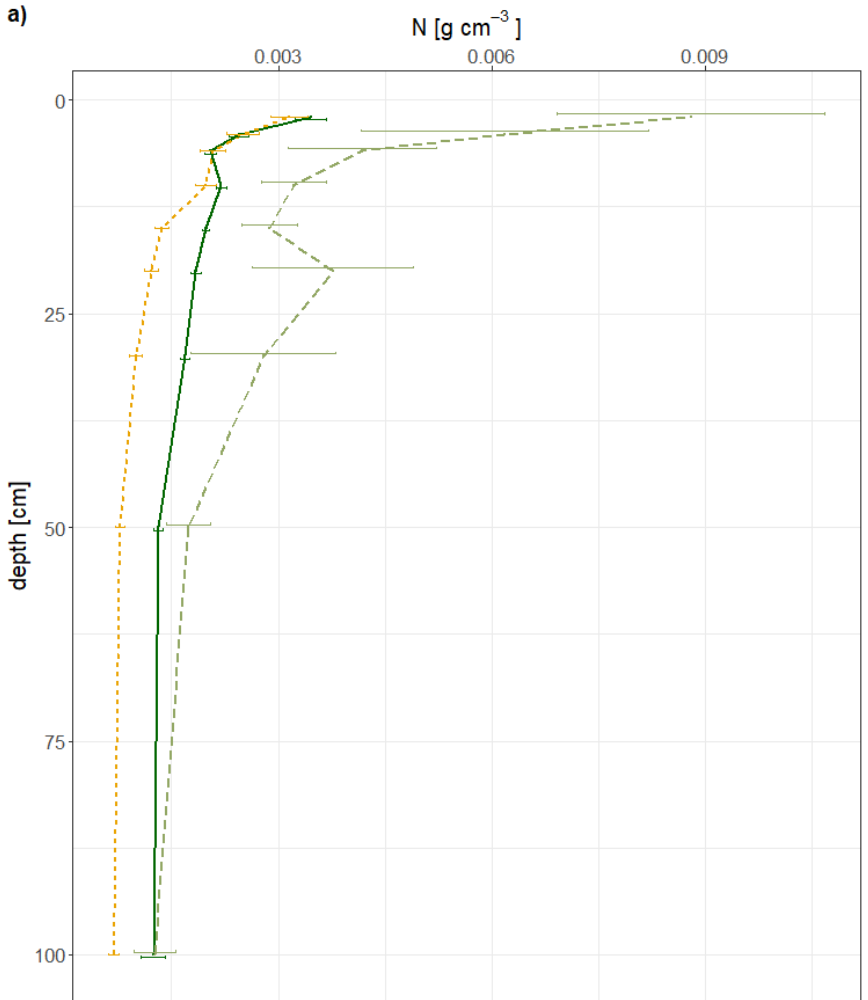

b)

$\mathrm{C}: \mathrm{N}$

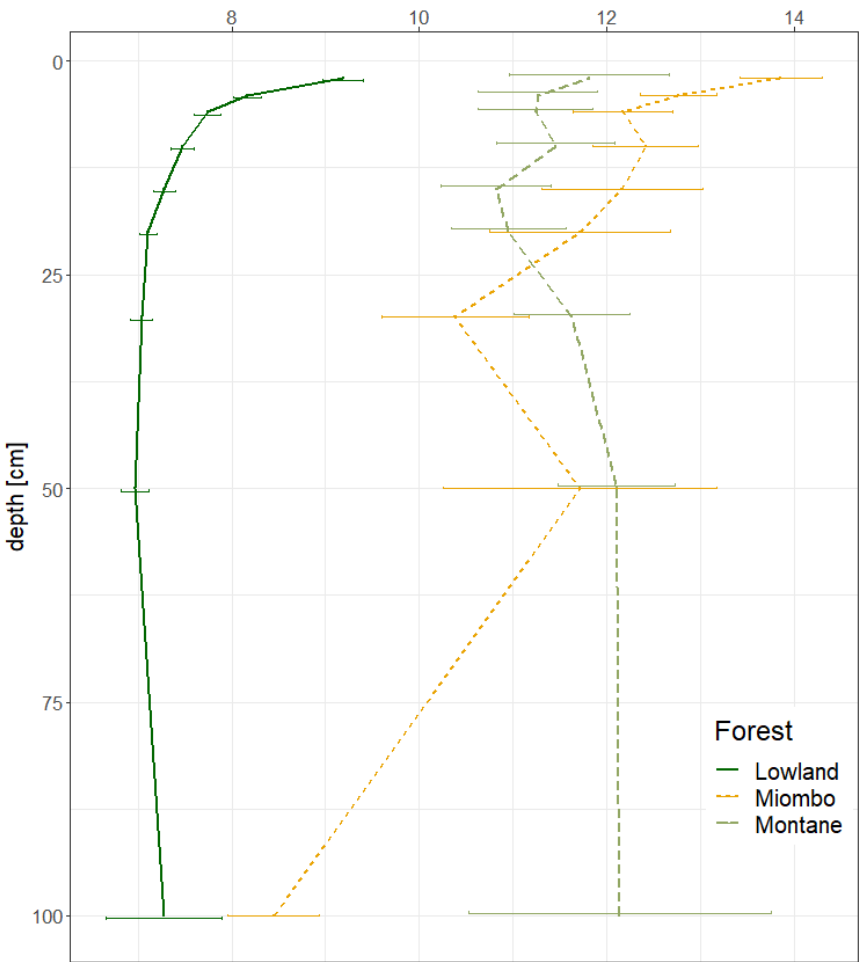

Figure S2: a) Profiles of average bulk $\mathrm{N}$ values in $\mathrm{g} \mathrm{cm}^{-3}$ for the three different forest sites. b) Profiles of average $\mathrm{C}$ : $\mathrm{N}$ ratios for the different forest sites. Error bar indicate standard error.

\section{References}

Lachouani, P., A. H. Frank, and W. Wanek. 2010. A suite of sensitive chemical methods to determine the d15N of ammonium, nitrate and total dissolved $\mathrm{N}$ in soil extracts. Rapid Communications in Mass Spectrometry: RCM 24:3615-3623.

Mulvaney, R. L. 1996. Nitrogen-inorganic forms. Pages 1123-1184 in D. L. Sparks, editor. Methods of soil analysis. Part 3. Chemical methods. American Society of Agronomy, Madison, Wisconsin, USA. 